\title{
Fracture of underwater notched structures
}

\author{
M.M. Mirsayar ${ }^{a^{*}}$ and Behrouz Takabi
}

${ }^{a}$ Zachry Department of Civil Engineering, Texas A\&M University, College Station, TX 77843-3136, USA ${ }^{b}$ Department of Mechanical Engineering, Texas A\&M University, College Station, TX 77843, USA

\begin{tabular}{l}
\hline A R T I C L E I N F O \\
\hline Article history: \\
Received 6 September, 2015 \\
Accepted 20 December 2015 \\
Available online \\
21 December 2015 \\
\hline Keywords: \\
Underwater structures \\
V-notch \\
Fracture \\
Hydrostatic pressure
\end{tabular}

\begin{abstract}
A B S T R A C T
Underwater structures are subjected to hydrostatic pressure during their service life. Sharp Vnotched components can be seen as a part of many underwater structures. For example, welded components, machined parts, gears, screws and bolts are among the well-known elements that contain sharp V-notches. The notch tip is a likely zone for initiation of cracks due to high stress/ strain concentration. The reliability analysis of the V-notched components requires a good understanding of stress/ strain distribution near the notch tip. The fracture initiation of the Vnotched components can be controlled by the tangential strain field near the notch tip. The tangential strain distribution and fracture initiation conditions are studied in this paper for notched components subjected to hydrostatic pressure. The effect of each tangential strain term on fracture initiation angle as well as tangential strain distribution around the notch tip is investigated using finite element simulation of a V-notched semi-circular specimen. It is shown that not only the singular terms, but also the "constants train field" significantly influence on tangential strain distribution and fracture initiation angle around the notch tip. The results of this paper can be used for standardization of the fracture in underwater structures containing V-notched components.
\end{abstract}

\section{Introduction}

One of the most crucial difficulties on designing underwater structures is limiting their stresses under allowable stress criteria; because they are under hydrodynamic loads in their entire life. For this purpose, some researchers (Nayebi \& Ansari, Sadrabadi, 2013; Takabi, 2016) have utilized modern and advanced materials such as FG materials to decrease stresses of structures. However, when it comes to notches, especially in underwater structures, material enhancement could not work out per se, and a meticulous study should also be performed on notched components. Notched components are seen in many engineering structures ranging from micro scale to macro scale. When the radius of the notch tip is very small compared to the length of its sides, the notch is considered as sharp. Cracks are introduced as a special case of notches mathematically, in which the notch angle is zero. In a V-notched component

\footnotetext{
* Corresponding author. Tel.: +1 (979) 777-6096

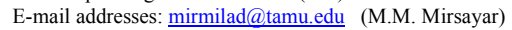


subjected to external mechanical loading, the state of the stress/ strain becomes singular at the notch tip which means the stress/ strain field approaches infinity adjacent the notch tip, mathematically. However, it is impossible to reach infinite stress/strain in a real material and hence, micro-cracks develop in an area, called fracture process zone, around the notch tip. The stress/ strain field evaluation at the notch tip is very important because fracture may initiate from the weakened area at the notch tip by increasing external mechanical loading which may finally result in catastrophic failure of the whole structures.

The elastic stress and strain fields around V-notch tip and crack tip have been extensively been investigated by many researchers in the past (Seweryn, 1994; Qian, 2001; Seweryn \& Lukaszewicz, 2002; Susmel \& Taylor, 2008; Ayatollahi et al., 2006, 2010a,b, 2011a, 2013; Ayatollahi \& Mirsayar, 2011; Abd-Elhady, 2013; Ayatollahi \& Aliha, 2007, 2008 a, b, 2009, 2011; Ameri et al., 2012, Arabi et al., 2013; Mirsayar \& Samaei, 2013, 2014, 2015; Lazzarin et al., 2010; Gomez et al., 2008; Mirsayar, 2013, 2014a,b,c, 2015a; Aliha et al., 2015a, b; Torabi, 2013; Mirsayar et al., 2014). Among them, Mirsayar et al. (2014) and Ayatollahi et al. (2011a) have studied the effect of first non-singular stress term on the stress distribution as well as the fracture initiation angle around the tip of a notch existing at the interface of two dissimilar materials. However, these studies are mainly focused on V-notches subjected to remote mechanical loading and the V-notches subjected to surface tractions have rarely been studied. Qian (2001) obtained the stress field equations for an interface notch with surface shear and normal tractions. He pointed out that surface tractions could be presented as a constant stress field around the notch tip and may influence on the stress distribution around the interface notch tip. However, the effect of surface tractions on the strain field and fracture initiation condition around the notch tip has not been investigated yet.

Several fracture criteria have been proposed so far to investigate fracture initiation conditions at the notch tip. These criteria can basically be classified into three different groups: energy based, stress based and strain based approaches (Erdogan \& Sih, 1963; Sih, 1974; Chang, 1981; Selvarathinam \& Goree, 1998; Mirsayar, 2015b). Among the energy based facture criteria, the maximum strain energy density criterion (Sih, 1974) is widely used by the researches and claims that fracture initiates at the notch tip in direction where the strain energy reaches its maximum value. The maximum tangential stress criterion (Erdogan \& Sih, 1963) is a well-established stress based criterion which says that fracture propagates at the critical distance $\left(r_{c}\right)$ from notch tip in direction where tangential stress $\left(\sigma_{\theta \theta}\right)$ reaches the ultimate strength $\left(\sigma_{\mathrm{c}}\right)$ of the material. Similarly, the maximum tangential strain (MTSN) criterion claims that fracture occurs at the critical distance from the notch tip in direction where tangential strain $\left(\varepsilon_{\theta \theta}\right)$ attains its ultimate tensile strain $\left(\varepsilon_{c}\right)($ Chang, 1981). However, all of these traditional fracture criteria only consider the singular stress/ strain field and the effects of non-singular terms are ignored.

In this paper, the role of constant strain term, induced from normal surface tractions (hydrostatic pressure), on the tangential strain field as well as fracture initiation angle around the notch tip is studied. It is shown that the constant strain field significantly influences on the tangential strain field around notch tip. Also, the significant effect of constant strain field on the fracture initiation direction is highlighted.

\section{Elastic field equations around V-notch tip}

Fig. 1 shows the schematic of a sharp V-notch subjected to both remote mechanical loading and normal surface tractions (hydrostatic pressure) alo $\mid g$ its edges. Williams (1952) studied the stress field equation around the $\mathrm{V}$-notch tip using linear elastic fracture mechanics (LEFM) assumptions. According to this work, the stress field around the notch tip subjected to remote external loading can be expressed in terms of the so-called Williams series expansions(Williams, 1952; Ju \& Chung, 2007) as; 


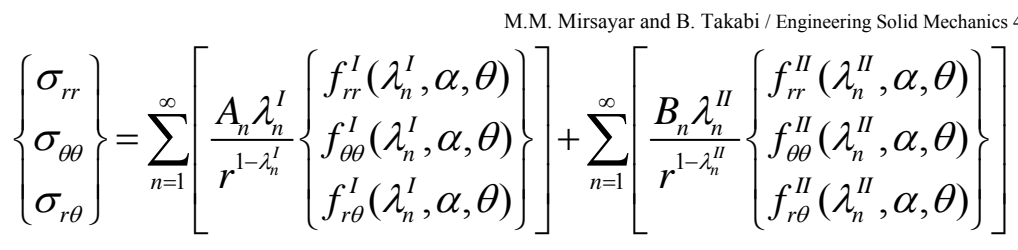

where $r$ and $\theta$ are the polar coordinates with the origin at the notch tip(see Fig. 1), $n$ is the order of term in the infinite series and $\alpha$ is the wedge angle.

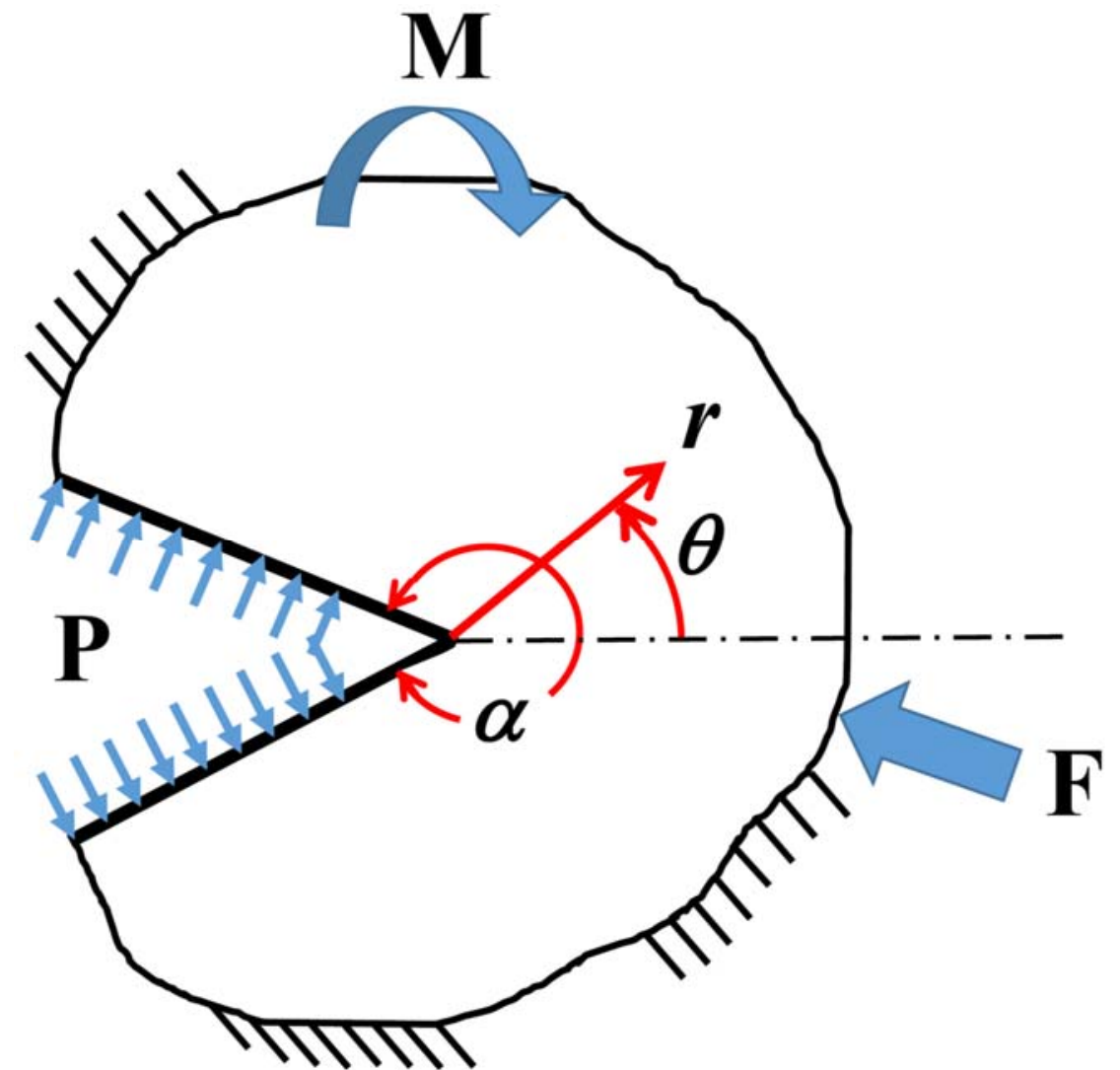

Fig. 1. Schematic of a sharp V-notch subjected to remote mechanical loading together with a surface hydrostatic pressure.

The parameters $\lambda_{I}^{n}$ and $\lambda_{I I}^{n}$ are mode I and mode II eigenvalues, obtained from positive roots of the following characteristic equation, which respectively represent opening and sliding mode of deformation at the notch tip.

$$
\begin{aligned}
& \lambda_{n}^{I} \sin (\alpha)+\sin \left(\lambda_{n}^{I} \alpha\right)=0 \\
& \lambda_{n}^{I I} \sin (\alpha)-\sin \left(\lambda_{n}^{I I} \alpha\right)=0
\end{aligned}
$$

The Eq. (1) is only valid for real values of the eigenvalues and as a result, the corresponding stress intensity factors, $A_{n}$ and $B_{n}$, are real numbers. The functions $f_{i j}^{k}\left(\lambda_{n}^{k}, \alpha, \theta\right)$ are kwon functions which represent variation of the stress field in tangential direction and are given in Ayatollahi and Nejati (2011) $((i, j) \equiv(\mathrm{r}, \theta)$ and $k \equiv(I, I I))$. For $n=1$, the coefficients $A_{1}$ and $B_{1}$ are related to the singular terms and are called mode I and mode II stress intensity factors respectively.

Qian (2001) indicated that for an interface notch problem subjected to combined shear and normal surface tractions, a particular solution should be added to the conventional solution. According to this 
work, the particular solution is corresponding to $\lambda=1$ which leads a stress term independent from radial distance $(\lambda-1=0)$, called "constant stress term". For notch problem in a homogeneous media subjected to only hydrostatic pressure $(p)$ boundary conditions, the radial, tangential and shear components of constant stress term can be given as;

$$
\left\{\begin{array}{c}
\sigma_{r r}^{0} \\
\sigma_{\theta \theta}^{0} \\
\sigma_{r \theta}^{0}
\end{array}\right\}=\left\{\begin{array}{c}
1+\cos [\alpha-2 \theta] \\
1-\cos [\alpha-2 \theta] \\
\sin [\alpha-2 \theta]
\end{array}\right\} A_{01}+\left\{\begin{array}{c}
\cos [\alpha-2 \theta] \\
-\cos [\alpha-2 \theta] \\
\sin [\alpha-2 \theta]
\end{array}\right\} p
$$

where, the coefficient $A_{01}$ is presented as;

$$
A_{01}=4 p\{-1+\alpha \sin (2 \alpha)+\cos (2 \alpha)\} \text {. }
$$

Therefore, the stress field around the notch tip in presence of the hydrostatic pressure on the edges of the notch can be presented in terms of summation of the general solution, Eq.(1), and the particular solution, Eq. (3). In Eq. (1), the terms corresponding to eigenvalues $\lambda_{I, I I}^{n}<1$ are called singular terms because these terms approach infinity when $r \rightarrow 0$. That means the singular terms play more important role than higher order terms in stress and strain distribution around the notch tip.

\section{Maximum tangential strain fracture criterion}

In this study, the maximum tangential strain fracture criterion (MTSN), proposed by Chang (1981), is employed to investigate fracture initiation angle around the notch tip. According to MTSN criterion, fracture occurs in the direction, $\theta_{0}$, where the tangential strain, $\varepsilon_{\theta \theta}$, reaches its maximum value, $\varepsilon_{T}$, at a critical distance, $r_{c}$, from the notch tip. The criterion could simply be represented as:

$$
\begin{aligned}
& \left\{\begin{array}{l}
\left.\frac{\partial \varepsilon_{\theta \theta}}{\partial \theta}\right|_{r=r_{c} ; \theta=\theta_{0}}=0 \\
\left.\frac{\partial^{2} \varepsilon_{\theta \theta}}{\partial \theta^{2}}\right|_{r=r_{c} ; \theta=\theta_{0}}<0
\end{array}\right. \\
& \varepsilon_{\theta \theta}\left(r_{c}, \theta_{0}\right)=\varepsilon_{T}=\sigma_{T} / E,
\end{aligned}
$$

where, $\sigma_{T}$ is the tensile fracture strength and $E$ is the Young's modulus of material. The critical distance $r_{c}$ could be considered as damaged zone around the notch tip which is a material property (Taylor, 2008; Ayatollahi \& Aliha 2008). Because we are using LEFM assumptions (which is a valid for brittle materials), the strain field around notch tip can be obtained using Hook's law as follows;

$$
\varepsilon_{\theta \theta}=\frac{1}{E}\left(\sigma_{\theta \theta}-v \sigma_{r r}\right)
$$

where $v$ is the Poisson's ratio of the material. Using Eq. (1), Eq. (3) and Eq. (7), it can be concluded that constant "stress" term leads to a constant "strain" term.

\section{Numerical example and discussion}

In order to study the effect of constant strain term, induced from surface hydrostatic pressure on the tangential strain distribution as well as fracture propagation angle, a finite element (FE) simulation is performed on a V-notched semi-circular specimen. The specimen, shown in Fig. 2(a), is a centrally notched semicircular disc of radius $R=40 \mathrm{~mm}$ with notch depth of $h=20 \mathrm{mmand}$ notch angle of $\gamma=30^{\circ}$ $\left(\gamma=360^{\circ}-\alpha\right)$. The specimen is subjected to hydrostatic pressure, $p=1 \mathrm{MPa}$, normal to the notch edges as well as one of its sides. The detailed loading and boundary conditions is shown in Fig. 2 (b). 


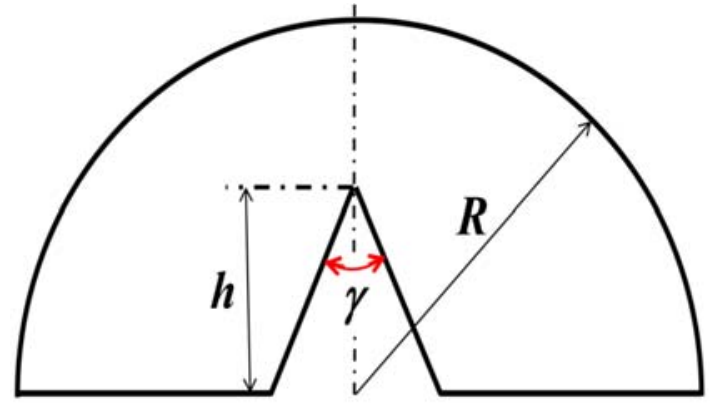

Fig. 2. Semicircular notched specimen a) general configuration, b) loading and boundary conditions

Fig. 3 shows the typical FE mesh used for modeling the specimen and the closer view of the elements adjacent the notch tip. A very fine mesh was utilized in the region near the tip due to high stress/ strain gradient in that area. In the FE analyses, 6-node quadratic triangular elements were used for the first row of elements surrounding the notch tip and 8-node quadratic quadrilateral elements were utilized for the rest of the model. The plane strain conditions and the thickness of unity were assumed. The stress intensity factors corresponding to the singular term associated with $\gamma=30^{\circ}(\lambda=0.51)$ was calculated using finite element over-deterministic (FEOD) approach. This method has successfully been used for calculation of the stress intensity factors of cracks and notches in both homogeneous and bi-material media (Ayatollahi et al., 2010; Ayatollahi \& Nejati, 2011).

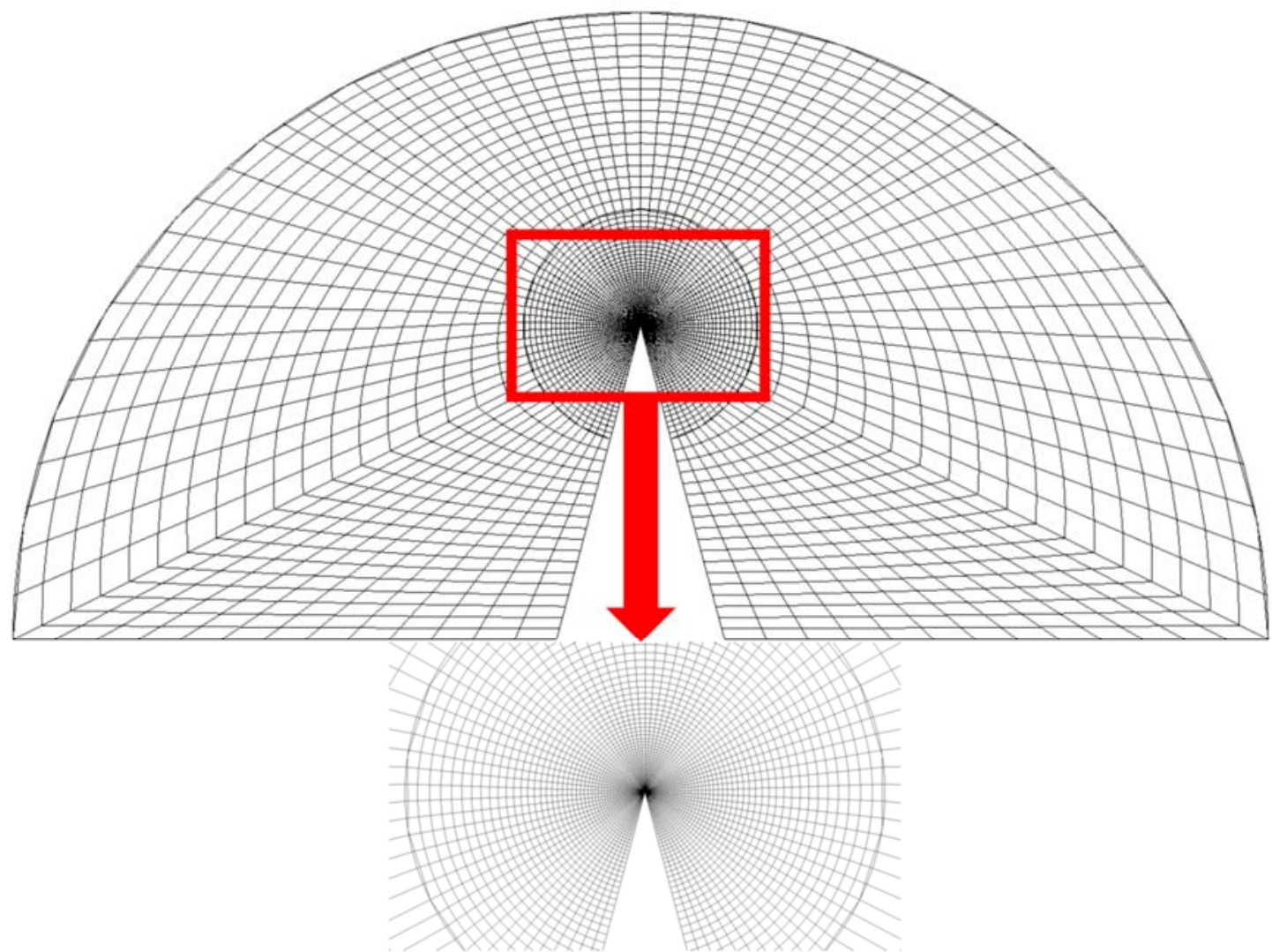

Fig. 3. A typical FE mesh used for modeling of V-notched semicircular specimen with $\gamma=30^{\circ}$ 
Fig. 4 shows the distribution of the tangential strain field throughout deformed shape of the specimen. The closer view of this contour of plot reveals that a high concentration in strain field exists at the notch tip.

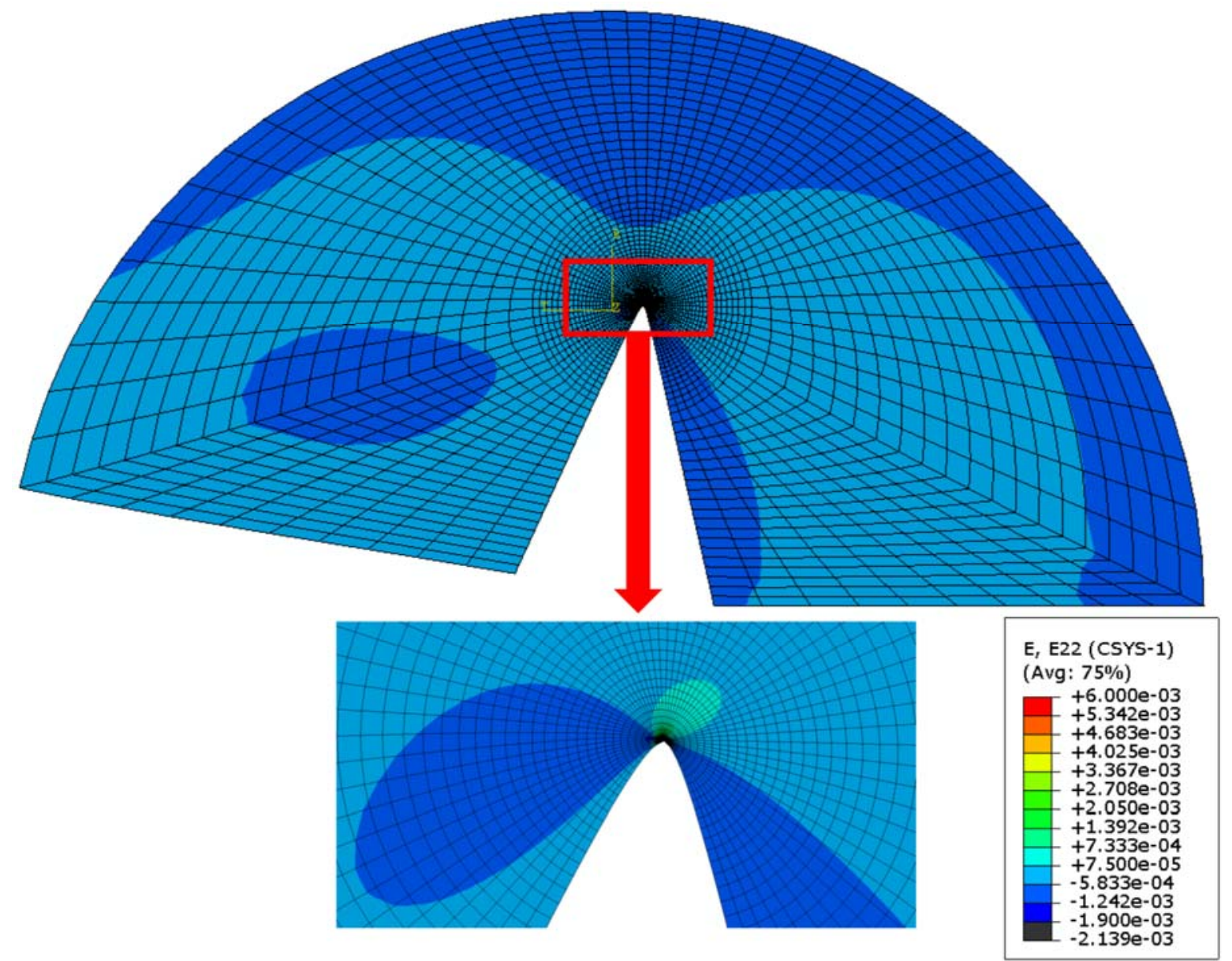

Fig. 4. Contour of plots for tangential strain distribution throughout the deformed shape of semicircular notched disc specimen together with a closer view around notch tip

The asymmetry in deformation of nodes at the notch tip is in agreement with asymmetry in loading and boundary condition. It can be seen from Fig. 4 that maximum tangential strain occurs around notch tip in direction $\theta_{0}<0^{\circ}$. However, according to Eq. (5), the direction of the fracture initiation depends on the critical distance, $r_{c}$, where the tangential strain component is evaluated. According to the literature (Ayatollahi \& Aliha, 2008, 2011; Aliha et al., 2010, 2012; Aliha \& Ayatollahi, 2012, 2013, 2014, Akbardoost et al., 2014; Ayatollahi et al., 2006, 2011b), the critical distance parameter may have different values for different brittle and quasi-brittle materials like, ceramics (within the range of 0.068 $\mathrm{mm}$ and $0.5 \mathrm{~mm}$ ), brittle polymers (e.g. PMMA with $r_{\mathrm{c}}$ in the range of 0.05 and $0.2 \mathrm{~mm}$ ), graphite $\left(r_{c}\right.$ $=0.35 \mathrm{~mm}$ and $r_{c}=0.47 \mathrm{~mm}$ for graphite 7477and graphite SA, respectively) or rocks ( $r_{c}=2$ to $6 \mathrm{~mm}$ ). In the present work, a typical critical distance of $0.18 \mathrm{~mm}$ is selected. In other words, it is assumed that crack propagates at a critical distance of $0.18 \mathrm{~mm}$ from notch tip. Fig. 5 illustrates the variations of tangential strain versus tangential direction of $\theta$ at a circular path of radius $r=0.18 \mathrm{~mm}$ from the notch tip. It can be seen that considerable errors exist between the strain distributions calculated by considering only singular solution and those of directly obtained from FE analysis (which considers all terms of the Williams series expansion given in Eq. (1)). The predicted values for angle of the fracture initiation, $\theta_{0}$, at the critical distance of $r=0.18 \mathrm{~mm}$ are also shown in Fig. 5. A substantial difference 
can be seen between fracture initiation angles estimated by only considering singular strain field $\left(-1.7^{\circ}\right)$ and FE results $\left(-19.2^{\circ}\right)$. However, by adding the constant strain field to the singular solution, a very good consistency can be observed between the theoretical predictions and FE analysis for distribution of the tangential strain field as well as the estimated fracture initiation angle. The distribution of the tangential strain field along radial direction of $\theta_{0}=-19.2^{\circ}$ is also shown in Fig. 6 . It is seen that constant strain term significantly influences on the strain field even in the very near the notch tip. It can also be realized that the higher nonsingular strain terms (corresponding to $\lambda>1$ ) have no effect on the strain distribution for radial distances less than $1 \mathrm{~mm}$ from notch tip. Finally, it can be concluded that the constant strain term may play an important role in prediction of the fracture initiation direction as well as the strain field distribution around notch tip.

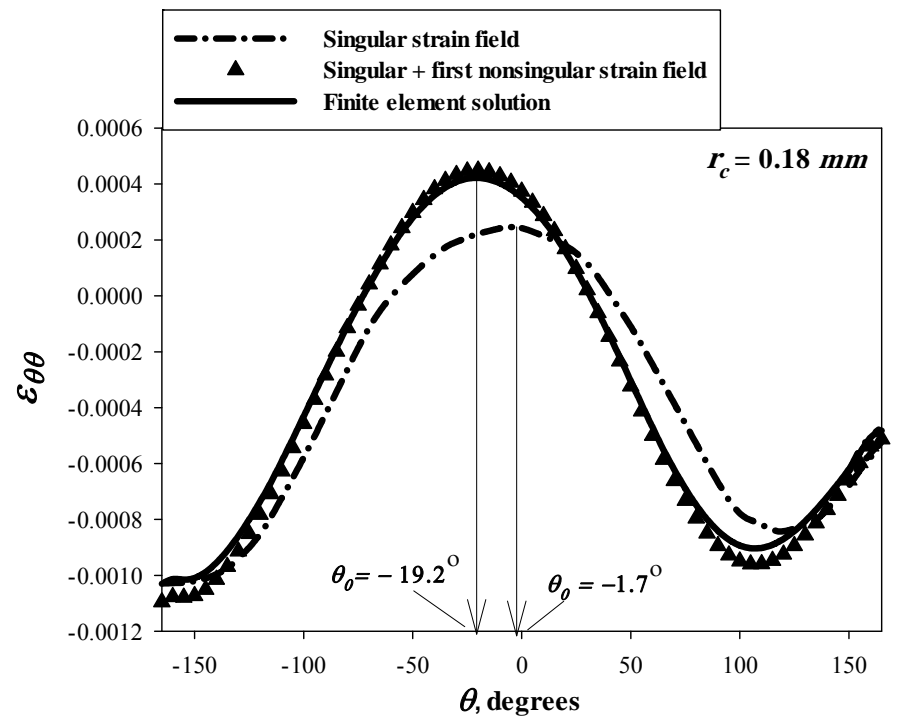

Fig. 5. Variation of tangential strain fields versus $\theta$ at a circular path of radius $r=r_{c}=0.18 \mathrm{~mm}$ from the notch tip

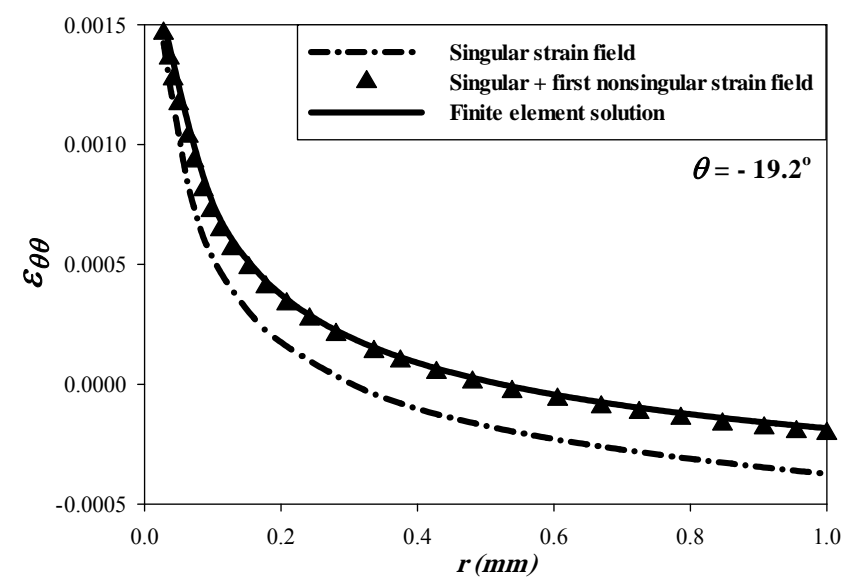

Fig. 6. Variation of tangential strain fields versus radial distance along $\theta=-19.2^{\circ}$

\section{Conclusions}

The fracture initiation in V-notched components subjected to hydrostatic pressure was studied in this paper. It was shown that the constant strain term, which causes as a result of hydrostatic pressure along the notch edge, significantly influences on the tangential strain distribution around the notch tip. The remarkable effect of constant strain term on the evaluation of the fracture initiation angle using the 
MTSN criterion was also indicated. Finally, it was concluded that one should consider the effect of constant strain term when studying fracture initiation in under water structures containing V-notched components. Since no recommendation is currently given in standards for the studied problem, the results of this work can be useful for standardization of the underwater notched structures.

\section{References}

Abd-Elhady, A. (2013). Mixed mode I/II stress intensity factors through the thickness of disc type specimens. Engineering Solid Mechanics, 1(4), 119-128.

Akbardoost, J. (2014). Size and crack length effects on fracture toughness of polycrystalline graphite. Engineering Solid Mechanics, 2(3), 183-192.

Aliha, M. R. M., \&Ayatollahi, M. R. (2008). On mixed-mode I/II crack growth in dental resin materials. Scripta Materialia, 59(2), 258-261.

Aliha, M. R. M., Ayatollahi, M. R., Smith, D. J., \&Pavier, M. J. (2010). Geometry and size effects on fracture trajectory in a limestone rock under mixed mode loading. Engineering Fracture Mechanics, 77(11), 2200-2212.

Aliha, M. R. M., Ayatollahi, M. R., \& Akbardoost, J. (2012a). Typical upper bound-lower bound mixed mode fracture resistance envelopes for rock material. Rock mechanics and rock engineering, 45(1), 65-74.

Aliha, M. R. M., \&Ayatollahi, M. R. (2012). Analysis of fracture initiation angle in some cracked ceramics using the generalized maximum tangential stress criterion. International Journal of Solids and Structures, 49(13), 1877-1883.

Aliha, M. R. M., \& Ayatollahi, M. R. (2013). Two-parameter fracture analysis of SCB rock specimen under mixed mode loading. Engineering Fracture Mechanics, 103, 115-123.

Aliha, M. R. M., \& Ayatollahi, M. R. (2014). Rock fracture toughness study using cracked chevron notched Brazilian disc specimen under pure modes I and II loading-A statistical approach. Theoretical and Applied Fracture Mechanics, 69, 17-25.

Aliha, M. R. M., Bahmani, A., \&Akhondi, S. (2015a). Numerical analysis of a new mixed mode I/III fracture test specimen. Engineering Fracture Mechanics, 134, 95-110.

Aliha, M. R. M., Bahmani, A., \&Akhondi, S. (2015b). Determination of mode III fracture toughness for different materials using a new designed test configuration. Materials \& Design, 86, 863-871.

Ameri, M., Mansourian, A., Pirmohammad, S., Aliha, M. R. M., \& Ayatollahi, M. R. (2012). Mixed mode fracture resistance of asphalt concrete mixtures. Engineering Fracture Mechanics, 93, 153167.

Arabi, H., Mirsayar, M. M., Samaei, A. T., \& Darandeh, M. (2013). Study of characteristic equation of the elastic stress field near bimaterial notches. Strength of Materials, 45(5), 598-606.

Ayatollahi, M. R., Aliha, M. R. M., \&Hassani, M. M. (2006). Mixed mode brittle fracture in PMMAan experimental study using SCB specimens. Materials Science and Engineering: A, 417(1), 348356.

Ayatollahi, M. R., \&Aliha, M. R. M. (2007). Wide range data for crack tip parameters in two disc-type specimens under mixed mode loading. Computational materials science, 38(4), 660-670.

Ayatollahi, M. R., \& Aliha, M. R. M. (2008a). Mixed mode fracture analysis of polycrystalline graphite-a modified MTS criterion. Carbon, 46(10), 1302-1308.

Ayatollahi, M. R., \&Aliha, M. R. M. (2008b). On the use of Brazilian disc specimen for calculating mixed mode I-II fracture toughness of rock materials. Engineering Fracture Mechanics, 75(16), 4631-4641.

Ayatollahi, M. R., \& Aliha, M. R. M. (2009). Analysis of a new specimen for mixed mode fracture tests on brittle materials. Engineering Fracture Mechanics, 76(11), 1563-1573.

Ayatollahi, M. R., \& Aliha, M. R. M. (2011). Fracture analysis of some ceramics under mixed mode loading. Journal of the American Ceramic Society, 94(2), 561-569.

Ayatollahi, M. R., \&Mirsayar, M. M. (2011). Kinking angles for interface cracks. Procedia Engineering, 10, 325-329. 
Ayatollahi, M. R., Mirsayar, M. M., \&Nejati, M. (2010). Evaluation of first non-singular stress term in bi-material notches. Computational Materials Science, 50(2), 752-760.

Ayatollahi, M. R., Mirsayar, M. M., \&Dehghany, M. (2011a). Experimental determination of stress field parameters in bi-material notches using photoelasticity. Materials \& Design, 32(10), 49014908.

Ayatollahi, M. R., Aliha, M. R. M., \& Saghafi, H. (2011b). An improved semi-circular bend specimen for investigating mixed mode brittle fracture. Engineering Fracture Mechanics, 78(1), 110-123.

Ayatollahi, M. R., \&Nejati, M. (2011). Determination of NSIFs and coefficients of higher order terms for sharp notches using finite element method. International Journal of Mechanical Sciences, 53(3), 164-177.

Ayatollahi, M. R., Dehghany, M., \& Mirsayar, M. M. (2013). A comprehensive photoelastic study for mode I sharp V-notches. European Journal of Mechanics-A/Solids, 37, 216-230.

Berto, F., Lazzarin, P., \& Radaj, D. (2009). Fictitious notch rounding concept applied to sharp Vnotches: Evaluation of the microstructural support factor for different failure hypotheses: Part II: Microstructural support analysis. Engineering Fracture Mechanics, 76(9), 1151-1175.

Chang, K. J. (1981). On the maximum strain criterion - a new approach to the angled crack problem. Engineering Fracture Mechanics, 14(1), 107-124.

Erdogan, F., \&Sih, G. C. (1963). On the crack extension in plates under plane loading and transverse shear. Journal of Fluids Engineering, 85(4), 519-525.

Gómez, F. J., Elices, M., Berto, F., \& Lazzarin, P. (2008). A generalised notch stress intensity factor for U-notched components loaded under mixed mode. Engineering Fracture Mechanics, 75(16), 4819-4833.

Ju, S. H., \& Chung, H. Y. (2007). Accuracy and limit of a least-squares method to calculate 3D notch SIFs. International Journal of Fracture, 148(2), 169-183.

Lazzarin, P., Berto, F., \& Zappalorto, M. (2010). Rapid calculations of notch stress intensity factors based on averaged strain energy density from coarse meshes: theoretical bases and applications. International Journal of Fatigue, 32(10), 1559-1567.

Mirsayar, M. (2013). Calculation of stress intensity factors for an interfacial notch of a bi-material joint using photoelasticity. Engineering Solid Mechanics, 1(4), 149-153.

Mirsayar, M., \&Samaei, A. (2013). Photoelastic study of bi-material notches: Effect of mismatch parameters. Engineering Solid Mechanics, 1(1), 21-26.

Mirsayar, M. (2014a). A new mixed mode fracture test specimen covering positive and negative values of T-stress. Engineering Solid Mechanics, 2(2), 67-72.

Mirsayar, M. (2014b). A modified maximum tangential stress criterion for determination of the fracture toughness in bi-material notches-Part 1: Theory. Engineering Solid Mechanics, 2(4), $277-$ 282.

Mirsayar, M. M. (2014c). On fracture of kinked interface cracks-The role of T-stress. Materials \& Design, 61, 117-123.

Mirsayar, M. M., Aliha, M. R. M., \&Samaei, A. T. (2014). On fracture initiation angle near bi-material notches-Effects of first non-singular stress term. Engineering Fracture Mechanics, 119, 124-131.

Mirsayar, M., \& Samaei, A. (2014). Application of maximum tangential stress criterion in determination of fracture initiation angles of silicon/glass anodic bonds. Engineering Solid Mechanics, 2(3), 145-150.

Mirsayar, M. M. (2015a). Three dimensional investigation of mode i stress intensity factor variations in crack front using finite element method. American Journal of Engineering and Applied Sciences, $8(1), 11$.

Mirsayar, M. M. (2015b). Mixed mode fracture analysis using extended maximum tangential strain criterion. Materials \& Design, 86, 941-947.

Mirsayar, M. M., \& Samaei, A. T. (2015). Fracture Initiation at the Zirconia/Veneer Interface-A Finite Element Simulation. American Journal of Engineering and Applied Sciences, 8(3), 354.

Nayebi, A., \& Sadrabadi, S. A. (2013). FGM elastoplastic analysis under thermomechanical loading. International Journal of Pressure Vessels and Piping, 111, 12-20. 
Qian, Z. Q. (2001). On the evaluation of wedge corner stress intensity factors of bi-material joints with surface tractions. Computers \& Structures, 79(1), 53-64.

Selvarathinam, A. S., \& Goree, J. G. (1998). T-stress based fracture model for cracks in isotropic materials. Engineering Fracture Mechanics, 60(5), 543-561.

Seweryn, A. (1994). Brittle fracture criterion for structures with sharp notches. Engineering Fracture Mechanics, 47(5), 673-681.

Seweryn, A., \& Łukaszewicz, A. (2002). Verification of brittle fracture criteria for elements with Vshaped notches. Engineering Fracture Mechanics, 69(13), 1487-1510.

Sih, G. C. (1974). Strain-energy-density factor applied to mixed mode crack problems. International Journal of fracture, 10(3), 305-321.

Susmel, L., \& Taylor, D. (2008). The theory of critical distances to predict static strength of notched brittle components subjected to mixed-mode loading. Engineering Fracture Mechanics, 75(3), 534550.

Takabi, B. (2016). Thermomechanical transient analysis of a thick-hollow FGM cylinder. Engineering Solid Mechanics, 4(1), 25-32.

Taylor, D. (2008). The theory of critical distances. Engineering Fracture Mechanics, 75(7), 16961705.

Torabi, A. (2013). Wide range brittle fracture curves for U-notched components based on UMTS model. Engineering Solid Mechanics, 1(2), 57-68.

Williams, M. L. (1952). Stress singularities resulting from various boundary conditions. Journal of Applied Mechanics, 19(4), 526-528. 